\title{
El diagnóstico social como discurso experto en el área sociojurídica*
}

\section{Diagnosis as a specialized discourse in the sociallegal area}

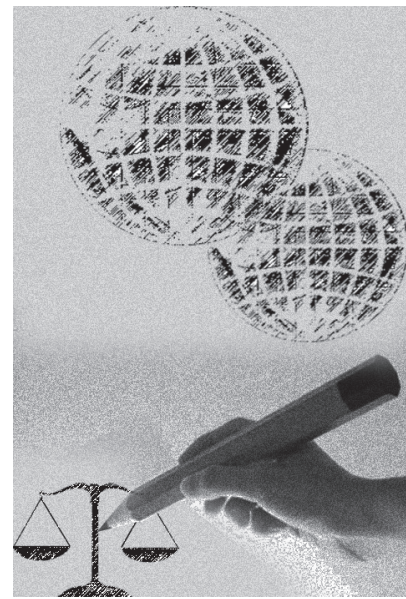

\section{Carolina González Laurino* Sandra Leopold Costábile ${ }^{* \star *}$}

Resumen: Como lectura de tercer orden sobre los sistemas expertos, este trabajo analiza la práctica del diagnóstico social en el sistema de protección social a la infancia y adolescencia en Uruguay, originada a partir de una derivación judicial.

A través de una mirada inicialmente incómoda, se busca promover el intercambio entre los especialistas que, desde el supuesto de una biografía que se construye reflexivamente, atribuye al sujeto la responsabilidad y los riesgos de sus conductas.

Palabras clave: Modernidad. Reflexividad. Confianza. Diagnóstico. Riesgo social.

\begin{abstract}
As third order reading on the expert systems, this work analyzes the practice of the social diagnosis in protection system in Uruguay, judicially originated. By supposing a reflectivity biography, social diagnosis attributes all responsibility and risks to the subjetc. This work seeks to promote a debate between specialist about theoretical support of their work.
\end{abstract}

Keywords: Modernity. Reflexivity. Confidence. Diagnosis. Social risk.

* Revisão de estilo e normatização por Sandra Valenzuela.

** Doctora en Sociología y Ciencias Políticas (opción Sociología). Licenciada en Sociología. Asistente Social. Docente e investigadora del Departamento de Trabajo Social. Facultad de Ciencias Sociales. Universidad de la República, Montevideo — Uruguay. E-mail: carolsoc@gmail.com

*** Magíster en Trabajo Social. Asistente Social. Cursando Doctorado en Ciencias Sociales con mención en Trabajo Social. Facultad de Ciencias Sociales. Universidad de la República, Uruguay. Docente e investigadora del Departamento de Trabajo Social. Facultad de Ciencias Sociales. Universidad de la República, Montevideo — Uruguay. E-mail: sleopold@ adinet.com.uy 


\section{Introducción}

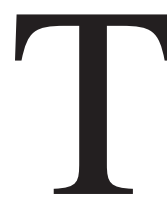

anto en el ámbito judicial como en el sistema de protección a la infancia y adolescencia, el diagnóstico social ${ }^{1}$ constituye una mirada de segundo orden frente a una situación problema que se somete a juicio experto. Esta práctica - que supone analizar situaciones sociales conflictivas a partir de códigos especializados — resulta habitual en los espacios de inserción profesional tradicionales. Menos familiar, resulta, sin embargo, la lectura que este trabajo propone; una lectura que se sitúa en el plano de la observación de la observación, en la expresión de Luhmann.

Por tanto, si el diagnóstico es una mirada de segundo orden sobre la situación vivenciada, la lectura que aquí se sugiere se ubica en un registro de tercer orden, que pretende tomar distancia del registro experto y situar el análisis del analista en el lugar del objeto estudiado.

Este sesgo de la mirada representa un pequeño movimiento que tiene enormes implicancias. Aunque ya acostumbrados después de tanto ejercicio, este "mirar atrás de cámaras" que implicó centrar la atención en el proceso de elaboración de un montaje cinematográfico, fue, al inicio, un tanto incómodo, tanto para el observado, como para un nuevo público desacostumbrado a develar los tecnicismos con los que se construían sus ilusiones.

El plano de la observación de la observación del experto es, por tanto, inicialmente incómodo para el analista y extraño para los sujetos a la mirada experta, quienes raramente conocen los resultados de un dictamen cuyo destinatario final resulta ser otro especialista.

Esta particularidad del destinatario del discurso experto trae consigo una cierta especialización en el lenguaje y en las categorías conceptuales utilizadas por

1. En el marco de este trabajo, se entiende como "diagnóstico social" a la lectura interpretativa de síntomas y signos de una situación social conflictiva, que se somete al juicio experto. Estos expertos pueden provenir de distintos ámbitos profesionales que, tanto en el ámbito judicial como en el sistema de protección social uruguayo, puede ser médico — generalmente médico forense o médico psiquiátrico —, como psicológico o social. El carácter "social" del diagnóstico no tiene pues, origen disciplinar, sino que pretende ser una calificación del tipo de situación sujeta a interpretación por distintos especialistas. Esta forma de caracterización del diagnóstico refiere consecuentemente a los debates acerca de la medicalización y la psicologización de los conflictos sociales, que están implícitos en este trabajo. 
el analista. Es lo que ha pasado con la caracterización de situaciones individuales y familiares bajo la terminología del riesgo social, como surge de las indagaciones realizadas en el marco de la investigación que da origen a este trabajo.

De esta forma, la especialización técnica en el diagnóstico viene de la mano de un aumento de precisión en la definición de los problemas por parte de los expertos y de un afinamiento progresivo en la metodología y en los instrumentos técnicos utilizados en la medición y en el análisis.

Sin embargo, esta mayor claridad y eficiencia en la delimitación de los asuntos parece correlacionarse positivamente con la opacidad de los supuestos que sostienen estos instrumentos operacionales, tanto para los profanos como para los expertos en este tipo de discursos. Por eso, al exponer la trama conceptual e ideológica de estos productos técnicos, este trabajo de investigación pretende plantear un debate que congregue a los especialistas a la discusión de las pretensiones de validez de sus producciones de saber.

De esta forma, más allá de poner a funcionar la necesaria vigilancia epistemológica sobre la producción de conocimiento en el área sociojurídica, un debate de estas características abre las posibilidades de intercambio al interior de los sistemas expertos sobre las implicancias políticas de estos discursos tanto en el sistema jurídico como en el sistema de protección social a la infancia y la adolescencia. ${ }^{2}$

\section{Los supuestos del análisis experto en el área sociojurídica}

En un contexto altamente especializado, la esencia de los sistemas expertos es la confianza que supone la convicción en la infalibilidad de los mecanis-

2. Este trabajo parte de una investigación realizada en el contexto de la edición 2008 de los Fondos Concursables Carlos Filgueira del Programa de Infancia y Familia del Ministerio de Desarrollo Social uruguayo, que se orientó al análisis de las prácticas diagnósticas de la institución de asistencia a la infancia y la adolescencia — producidas u ordenadas desde el ámbito judicial — como fuente de conocimiento acerca de las familias uruguayas.

A nivel metodológico, se tomaron como unidades de análisis los informes diagnósticos elaborados por el cuerpo técnico de los Juzgados de Familia Especializados y de la División de Estudio y Derivación del Instituto de la Niñez y la Adolescencia en Uruguay seleccionados en función de criterios aleatorios de análisis muestral cuya trayectoria se siguió desde el sistema judicial a la institución asistencial. 
mos que se ponen en juego en todos los sistemas abstractos, independientemente de poder tener a la vista los procesos que conducen a la verificación de los sistemas. La confianza que supone adoptar en la vida de los sujetos un conjunto de decisiones diarias que condicionan la realización de sus acciones conduce a la adopción de la perspectiva del cálculo de los riesgos (Giddens, 1995; Beck, 1997, 1998, 2001).

Por eso, cuando una persona recurre a un sistema experto como el judicial para resolver aspectos que hacen al manejo de sus bienes o a la configuración de su propia vida familiar, está depositando la confianza en que se active un mecanismo supraindividual de arbitraje de conflictos. Y, una vez activado, se somete a la decisión institucional que las reglas que administran este complejo sistema experto imponen, tanto a las acciones individuales, como a la propia denominación, configuración y ordenamiento de las relaciones sociales que se han puesto a consideración arbitral.

En el caso de la justicia, como sistema experto de arbitraje de conflictos personales, institucionales o de otra forma de relaciones y vínculos sociales, unos saberes especializados (por ejemplo, los jueces) recurren a otros (psicólogos, trabajadores sociales, psiquiatras, médicos forenses, calígrafos, ingenieros etc.) para establecer aproximaciones diagnósticas sobre la situación a resolver. En el escenario de la modernidad, la idoneidad en una materia no implica la experticia en otra aledaña, por lo que Giddens sostiene que "los sistemas abstractos son opacos para la mayoría" (1995: 46).

En este escenario, los diagnósticos sociales, debido a sus supuestos e implicancias, parecen apoyarse en la perspectiva de la modernidad reflexiva como soporte en la elaboración de sus dictámenes. Desde la idea de "modernidad reflexiva", Giddens habla de tres elementos para explicar el carácter dinámico de la vida social moderna: la separación entre tiempo y espacio, el desenclave de las instituciones sociales y la reflexividad generalizada (1995: 28-34).

No obstante, es la tercera de las características anunciadas por Giddens - el carácter reflexivo de la modernidad - lo que en este momento interesa subrayar. Tal carácter, supone, por una parte, una revisión constante de la mayoría de los aspectos de la vida social, como consecuencia de la permanente transformación del conocimiento. Por otra parte, como característica de la mo- 
dernidad tardía, la reflexividad constituye una inflexión en la forma de concebir los condicionamientos sistémicos o las determinaciones institucionales sobre el sujeto moderno.

Desde esta perspectiva, los actores sociales son capaces de sopesar las opciones y las consecuencias de sus actos mediante un proceso de análisis que los libera de las fuertes determinaciones institucionales y societales que constreñían sus decisiones. Esta mayor independencia en la búsqueda de herramientas con las que manejar su biografía otorgaría a los actores individuales y colectivos de un mayor poder de injerencia en sus asuntos, lo que, a la vez que más libres, los convertiría en responsables de sus propias decisiones. De este modo, esta capacidad de decisión sobre sus trayectorias personales y sociales los coloca enfrente a los múltiples riesgos que aparecen con la vida moderna. ${ }^{3}$

Partiendo de este nuevo escenario, los teóricos de la modernidad reflexiva invitan a pensar en la cuota parte que al individuo corresponde en la gestión de sus propias actitudes y conductas respecto a la eventualidad de distintos tipos de riesgo. El sujeto es visualizado frente a un abanico de opciones y al cálculo de sus posibles ganancias y riesgos en la construcción reflexiva de su propia biografía a la que se atribuye impacto universal. ${ }^{4}$

Por lo tanto, desde esta perspectiva, la identidad individual se entiende como el logro de un yo auténtico, internamente referencial, que se encuentra conectado significativamente a través de la íntima lealtad al proyecto reflejo del yo.

Sin embargo, esta perspectiva teórica que habla de un sujeto informado y autoconsciente en la construcción de su propia identidad, trae aparejadas algunas dificultades a la hora de la individualización de los riesgos en poblaciones

3. Como explica Giddens, el cálculo de riesgos y oportunidades en la vida del sujeto moderno, lo coloca frente a la posibilidad de adoptar una decisión informada y en pleno conocimiento de las consecuencias de su acción que hace posible la colonización del futuro. Giddens, Anthony. Modernidad e identidad del yo. Barcelona, Península, 1995. p. 166.

4. "Hasta aquí — sostiene Giddens — nuestro análisis nos lleva al mundo de las relaciones sociales externas al yo en función, casi siempre de su impacto reflejo sobre la identidad y el estilo de vida. Sin embargo, las decisiones personales afectan también a consideraciones universales (el nexo, en este caso, va de las personas al planeta)". (Giddens, 1995: 279.) 
excluidas, si consideramos el contexto de una sociedad heterogénea y desigual en la que se enmarcan las decisiones de los actores.

\section{De seguridades y riesgos: una perspectiva crítica}

En la descripción de los teóricos de la modernidad reflexiva no aparecen limitaciones a ese proceso de creciente reflexividad individual. No obstante, y pese a sucesivas aclaraciones de Giddens, ${ }^{5}$ la pregunta por el desarrollo autónomo del yo en condiciones sociales desventajosas aparece nuevamente pertinente. ¿Es posible pensar en un sujeto autónomo, comprometido con la decisión de su propia vida en proyección universal - como se plantea en la conceptualización de la política de la vida - cuando se habla de personas excluidas, desafiliadas - en la concepción de Castel — o precariamente incluidas en la vida social, económica, política y cultural de una sociedad nacional?

Plantear esta pregunta supone un doble riesgo. Por un lado, responder afirmativamente posiciona al analista en el lugar de la responsabilización individual de actitudes, comportamientos y representaciones sociales en las que habría que indagar cimientos sociales. Por otro lado, la respuesta negativa a la pregunta, corre el riesgo de comprometer al investigador, no sólo en la búsqueda mecánica de causas sociales de conductas individuales, sino en la producción de respuestas prefabricadas y de metas externas a los valores y deseos de personas pertenecientes a amplios sectores sociales con su consiguiente consideración de sus proyectos en situación de "minoridad" social.

No obstante, partir de la conceptualización que supone que todos los individuos tienen intrínsecamente la misma posibilidad de hacerse cargo de decisiones adoptadas libremente, aun en contextos de pobreza y exclusión social, como si esta situación no condicionara seriamente sus opciones de vida, sería

5. Esta objeción se encuentra explicitada en la introducción de Modernidad e identidad del yo: "Podría pensarse que con la expresión 'estilo de vida' nos referimos sólo a los logros de grupos o clases más favorecidas [...]. Los pobres quedarán más o menos excluidos de la posibilidad de realizar elecciones de estilo de vida". Sin embargo, Giddens sostiene que su reflexión abarca a todas las clases sociales, incluyendo contextos de privación social. (Giddens, 1995: 14.) 
caer en la ingenuidad de ignorar la producción social de las desigualdades en un sistema de clases.

Las opciones individuales, y en este punto puede completarse el análisis de Giddens, son históricamente situadas y contextualizadas en sociedades modernas complejas.

Asimismo, desde otras perspectivas teóricas (Castel, 2004) se observa con preocupación, el carácter deficitario de este proceso de creciente reflexividad individual, en una época en la que, al mismo tiempo que se incrementa la generación de riesgos, se fragilizan los soportes colectivos. ${ }^{6}$

Al debilitamiento de la protección clásica, Castel plantea la irrupción de una nueva generación de riesgos — riesgos industriales, tecnológicos, ecológicos, sanitarios, naturales etc. - cuya emergencia resulta del devenir de las ciencias y de las tecnologías que, en su particular desarrollo, parecerían haberse vuelto "contra" la naturaleza y el medio ambiente, generando así, un sentimiento de impotencia.

Castel señala que si consideramos el actual entramado de protecciones civiles y sociales ${ }^{7}$ que se han dispuesto - por lo pronto en las sociedades de los países desarrollados - seguramente éstas sean las sociedades más seguras que jamás hayan existido. Sin embargo, al mismo tiempo, y en forma perturbadora, las preocupaciones en torno a la seguridad se tornan omnipresentes. La "frustración sobre la situación de la seguridad" se deriva del hecho de que los programas de protección no sólo no son absolutamente eficientes, sino que, al mismo tiempo que dominan — relativamente - ciertos riesgos, hacen emerger otros nuevos.

Es en este sentido que puede comprenderse que "estar protegido es también estar amenazado", como afirma Castel (2004: 13), quien plantea que el

6. En este sentido, afirma Castel (2004) que dos series de transformaciones se conjugan y dan sostén a la problemática de la inseguridad. En primer lugar, señala la erosión de los sistemas de producción de seguridad "clásicos" que contrarrestaban los riesgos sociales en el marco de la sociedad salarial, sobre la base de condiciones de trabajos estables. Desde su perspectiva, el debilitamiento del Estado nacional más los cambios socioeconómicos generados desde mediados de los años 70 han producido un estado de inseguridad frente al porvenir, en el que también se ve incrementada la inseguridad civil.

7. Robert Castel (2004) distingue dos grandes tipos de protecciones. Las protecciones civiles son las que garantizan las libertades fundamentales y la seguridad de los bienes y de las personas en el marco de un Estado de Derecho. Las protecciones sociales "cubren" a los sujetos de los principales riesgos que puedan suponer una degradación de su situación vital: accidentes, enfermedad, vejez, pobreza. 
incremento de la sensibilidad ante los riesgos configura una búsqueda infinita y siempre frustrada de seguridad.

No es extraño, entonces, que la noción generalizada e indiferenciada del riesgo aportada tanto por Beck como por Giddens, contribuya teóricamente para denunciar el carácter obsoleto de los dispositivos clásicos de protección, precisamente en lo que refiere a su dimensión colectiva. A la vez que se insiste en la proliferación masiva de los riesgos, se efectiviza "una celebración del individuo aislado de sus inserciones colectivas, ‘desarraigado’ (disembedded), según la expresión de Giddens” (Castel, 2004: 82).

Por lo expuesto, en relación a los supuestos teóricos que informan los diagnósticos especializados en el área de la justicia, es pertinente formular algunas preguntas. ¿Es el modelo de hombre moderno y reflexivo, libre de decidir ante una serie de alternativas, quien aparece como supuesto de referencia en los diagnósticos sociales del sistema judicial y del sistema de protección social uruguayo? ¿O por el contrario, se expone - desde una perspectiva crítica a la individualización creciente — la dificultad experimentada por sujetos aislados en un contexto de fragilización de los soportes colectivos?

\section{La definición judicial del diagnóstico: ipara qué conocer?}

Construidas como espacios de producción de conocimiento - cabe recordar que la noción de conocimiento está presente en la etimología de diagnóstico - las prácticas sociales del diagnóstico y la observación se construyen socialmente como dominios de saber específicos que engendran nuevas formas de sujetos y nuevos sujetos de conocimiento (Foucault, 1991: 14). ${ }^{8}$

8. La mirada de Foucault sobre la producción de los discursos técnicos como fuentes de saber remite a la discusión sobre la construcción social de la verdad por parte de las ciencias humanas, que el autor ata a los métodos de indagación en el ámbito de la justicia y desarrolla en sus reflexiones sobre "La verdad y las formas jurídicas" (Foucault, 1991) o en su planteo sobre la configuración social de "los anormales" (Foucault, 2007). Dado que un análisis de estos temas excede los propósitos de estas reflexiones, se propone seguir estas pistas en nuevos trabajos que se enfoquen específicamente en la construcción de estos saberes especializados. 
A su vez, tal como advierte Marcelo Viñar, el diagnóstico no provee un conocimiento "descriptivo" e "inocuo", sino que resulta un conocimiento portador de un "poder eficaz de sanción y de consecuencias en cuanto a establecer el destino de aquellos a quienes se les aplica, que tiene un valor de anticipación, un valor predictivo [...]. El diagnóstico no sólo es portador de una fotografía del presente sino de una presunción anticipada sobre el futuro, sobre las consecuencias". (Viñar, 2004: 34)

Tanto como las resoluciones del juez, los informes diagnósticos elaborados por técnicos de otras especialidades en la esfera judicial constituyen espacios socialmente productivos para analizar las formas de arbitraje en los conflictos privados que buscan legitimidad jurídica.

Los sistemas abstractos refieren unos a otros en la búsqueda de insumos tecnoburocráticos para legitimar su quehacer y su saber (Giddens, 1995). Como ya fue dicho, el juez recurre al experto en distintas materias para solicitar su pericia en ámbitos en los que deberá arbitrar.

Los pareceres técnicos en el área de la salud física, mental o emocional o en la esfera de lo social, aparecen en los expedientes judiciales como opiniones calificadas que describen situaciones, analizan vínculos familiares y sociales, discriminan aspectos saludables y patológicos de las personas y sugieren caminos que recorrer.

En el caso de las instituciones judiciales analizadas, los peritajes técnicos se enmarcan en la urgencia y la perentoriedad de búsqueda de respuestas por parte del sistema. Los dispositivos pensados para la descripción de las situaciones, actúan, en este contexto, en forma tal, que queda al descubierto tanto su lógica de indagación en las historias personales, como las interpretaciones que estos sistemas expertos hacen de las trayectorias familiares.

La entrevista indagatoria finaliza con un informe dirigido al juez, donde se describe la situación individual y familiar, en una presentación que sobreexpone al sujeto y lo coloca en observación. Esta instancia que moviliza al entrevistado como sujeto que pone en juego sus inquietudes, emociones y deseos en relación a la instancia judicial que lo convoca, no resuelve su situación ni aporta mayor reflexividad a su biografía. No se trata de una instancia terapéutica, sino de la presentación de su problema ante un cuerpo especializado y burocra- 
tizado de funcionarios técnicos, cuya función se agota en el asesoramiento judicial. Se produce, de esta manera, un discurso con pretensión de verdad, que adquiere poder de arbitraje público en una instancia privada, donde el sujeto es convocado como mero informante (González, 2008).

Esta distancia intercultural que supone la relación con el otro que se pretende conocer, no se establece a partir de un espacio igualitario donde ambos sujetos tienen el control de la situación y establecen pretensiones de validez que el otro tiene posibilidad de aceptar o rebatir. En el caso del diagnóstico, es el técnico quien conoce, evalúa y emite opinión experta, dejando al otro en situación de subordinación ${ }^{9}$ (Castel, 1986).

El informe desplaza el discurso del entrevistado a un segundo plano, ya que su palabra es interpretada y resignificada desde un lenguaje experto que se aleja cada vez más de la comprensión y control de los sujetos involucrados. En este sentido, en las relaciones establecidas entre técnicos y entrevistados lo que prevalece es el poderío del que impone las reglas de juego sobre el otro (Viñar, 2004).

En este encuentro, de carácter asimétrico, entre técnico y entrevistado, no hay ni puede haber devolución de la mirada del experto sobre la situaciónproblema que el sujeto presenta, sino que ésta reaparece, transfigurada, en la palabra calificada del juez en la instancia de arbitraje. La palabra del juez adquiere, de esta forma, un significado absoluto como decisión supraindividual, estatal y pública con consecuencias en el mundo de la vida de los sujetos.

Estas decisiones arbitrales, que se inscriben en la biografía de las personas, no forman parte de un proceso de análisis compartido que promueva instancias reflexivas y emancipatorias, como sugieren los analistas del riesgo (Giddens, 1995; Beck, 1998). Se trata de una apelación a la autoridad que inviste la judicatura, abstracción que no está sometida a debate ni comparte el proceso de reflexión que la decisión lleva implícita. Al sujeto corresponde el acatamiento o la resistencia al mandato judicialmente establecido.

9. Viñar habla de tres ejes presentes en esta especial relación que une al experto que realiza el diagnóstico con su entrevistado: "un eje de conocimiento, otro de amor-odio y otro de sumisión y dominio", que funcionan entrelazados, y dan cuenta de la particularidad de esta vinculación que evidencia la asimetría de poder y la distancia cultural (Viñar, 2004: 35). 


\section{Descripción y evaluación: el peso del diagnóstico en las trayectorias institucionales de los niños y adolescentes uruguayos}

Cuando un niño o adolescente ingresa a la institución pública responsable de la asistencia social a través del dispositivo de captación judicial, viene precedido de un dictamen experto que da cuenta de una serie de factores psicológicos, económicos y sociales que lo colocan en situación de riesgo social.

Si durante la primera modernidad los dispositivos de regulación de las situaciones conflictivas se activaban mediante la identificación de un daño o peligro, en el contexto de la modernidad tardía aparecen una serie de políticas preventivas para el control de poblaciones que dan cuenta de la detección temprana de determinados factores de riesgo. La presencia de estos elementos, previamente tipificados por los sistemas expertos, constituyen indicadores que activan — automáticamente, dirá Castel — una señal de alerta que pone a funcionar una serie compleja de mecanismos de regulación social (1986).

Estas estructuras y dispositivos institucionales de control, que se ponen en juego mediante la prevención, dan cuenta de lo que Castel llama una "nueva modalidad de vigilancia" cuyo objetivo es "anticipar e impedir la emergencia de un suceso no deseable" (1986: 230).

El sujeto es pues, precedido de un conjunto de información que anticipa su conducta futura, predecible, para los sistemas expertos. Para esta prematura detección de futuros conflictos, dirá Castel, no hace falta la presencia de individuos concretos. El diagnóstico habla por ellos. Las lecturas expertas acumulan dictámenes técnicos que constituyen "historiales subterráneos" que anticipan la conducta de los sujetos en la "científica" fórmula de la prevención de futuros daños.

El diagnóstico anuncia y determina los trayectos individuales en una suerte de profecía que se autoconfirma mediante el recorrido de los individuos por instituciones que no los acogen, defienden o amparan, sino que los ratifican en la estigmatización y segregación social previas a su ingreso. Al final del recorrido institucional se comprueba lo que ya se sabía: un individuo caracterizado en función de determinados factores de riesgo, identificado en su condición de vulnerabilidad, con un recorrido errático por una institución que lo confina al 
desamparo afectivo, se aleja de la institución de asistencia a la infancia y la adolescencia cuando cumple su "mayoría de edad" en condiciones similares o peores a las de su ingreso y es captado por nuevas instituciones de vigilancia que se sostienen en versiones ideológicas del control similares a las que ya transitara durante sus primeros años de vida.

En esta política preventiva desaparece el sujeto que queda subsumido en "correlaciones estadísticas de elementos heterogéneos" a través de los cuales se "descompone al sujeto concreto de la intervención" que se reconstruye a partir de la mirada experta en la historia "clínica" de sucesivos diagnósticos que enumeran y describen su historia de vida por medio de un complejo cálculo de probabilidades (Castel, 1986: 231 y s.).

Este saber sobre el otro opera a través de un proceso de racionalización acerca de diferentes causalidades sociales - como el abandono, el maltrato, la pérdida de la capacidad de juicio de lo que es correcto e incorrecto, el conflicto de ciertas conductas con las disposiciones legales — que tiene implicaciones políticas.

Se trata de estereotipias racionalizadas y pragmáticas que operan en la actividad diagnóstica - tanto a nivel judicial como de política social - a través de una discriminación de factores de riesgo que no tiene como objetivo asistir al sujeto en su vulnerabilidad, sino imprimirle una marca para la elaboración de un perfil de predisposición a la conducta socialmente reprobable o — como bien lo describe el diagnóstico psiquiátrico en toda su dureza sancionatoria - "antisocial".

Esta señal, técnicamente impresa, acompaña al sujeto durante toda la trayectoria institucional, confirmándose en cada instancia de evaluación diagnóstica como un dispositivo que se activa automáticamente en cada episodio de la vida del sujeto que requiere de la intervención experta.

La evaluación situacional de los factores de riesgo, que determinan pronósticos acerca de los individuos que ingresan a las instituciones, sustituye el tratamiento como espacio de continuidad en la asistencia. Como anuncia Castel, en referencia a las nuevas políticas de prevención, se produce una transmutación de la actividad terapéutica en actividad pericial. 
Si bien la intervención del técnico sigue siendo esencial en el funcionamiento institucional, ya que el diagnóstico pericial marca las trayectorias individuales, la intervención experta se convierte en innecesaria respecto al proceso de asistencia: "Dicho de otro modo, un número creciente de sujetos deben seguir siendo vistos por los especialistas de los saberes médico-psicológicos cuya intervención continúa siendo requerida para evaluar sus capacidades (o su incapacidad). Pero, una vez vistos los individuos dejan de tener que ser seguidos por estos especialistas" (Castel, 1986: 236).

La mirada técnica "localiza" al sujeto, le pone una marca que no contribuye a aumentar su reflexividad — aspiración de los analistas del riesgo — ni lo acompaña en el proceso de autodescubrimiento, ni en la adaptación al hogar que lo recibe o en las distintas instancias de conflicto que supone la convivencia. La mirada del otro — portador del saber — reaparece en la biografía del sujeto cuando es requerida a partir de un desorden, una explosión, un "pasaje al acto" que requiere nuevamente de un diagnóstico y un pronóstico de su conducta futura.

Volviendo al planteo de Giddens respecto al proceso de individuación que trae consigo la reflexividad del yo, el autor hablaba de una construcción de una trayectoria vital que podría revisarse a través de una sucesión de "momentos" que forman parte de un itinerario reflejamente activado de autorrealización. La pregunta que surge es: ¿quién selecciona estos momentos significativos? Tanto a nivel judicial como en el contexto institucional de la protección social, la "selección" de estos momentos significativos en la vida de los niños y los adolescentes queda en manos del sistema especializado, que efectúa fotografías instantáneas donde establece el diagnóstico de situaciones complejas por las que atraviesa el sujeto en su crecimiento y desarrollo personal.

¿Corresponde a la administración de las instituciones la determinación de las intervenciones técnicas en la vida de los sujetos y al observador la ilación de estas situaciones de crisis?

¿Qué queda en pie de este proceso autorreflexivo en condiciones de institucionalización? ¿Qué ocurre con el acompañamiento terapéutico de estos procesos de desamparo que se han tipificado como "riesgosos" desde el punto de vista social? La información empírica parece indicar que la mirada técnica "no ve" más allá del síntoma. 


\section{Judicialización de los problemas sociales}

Las tendencias modernas al recurso de los sistemas abstractos como fuente de información para tomar decisiones arbitrales pueden observarse en la práctica del acceso al sistema judicial para la resolución de conflictos familiares y sociales.

En referencia a los asuntos familiares que se tratan en el ámbito de la justicia, se moldea una forma de producción de la verdad que aparece recubierta de abstracción y neutralidad. El sistema de justicia penetra en la vida íntima de los sectores más pobres regulando sus formas de hacer familia, de armar sus vínculos, de tomar decisiones acerca de la forma de criar a sus hijos.

El recurso al sistema de justicia se produce mediante la búsqueda de un arbitraje "imparcial" al que se le asigna la instancia de la deliberación y del juicio de las conductas en el ámbito privado. Desde la perspectiva de Foucault, se trata de una forma de producción de saber que no es inocua en la vida de los sujetos $(1991,2007)$.

En el caso de los Juzgados de Familia Especializados de Montevideo, es posible identificar dos caminos mediante los que se lleva a cabo la judicialización del conflicto familiar. Por un lado, las denuncias de las situaciones conflictivas surgen en instituciones públicas - sanitarias y educativas fundamentalmente - o en organizaciones de la sociedad civil, que plantean ante el sistema judicial una situación problemática en el ámbito de las familias a las que atienden. Asimismo, una segunda vía de denuncia se origina a nivel intrafamiliar, cuestionando el rol materno, el lugar del hijo en relación a la aceptación de límites o en torno al uso problemático de drogas.

Si la primera forma de acceso a la justicia puede explicarse en función del papel disciplinador de las instituciones que atienden a la infancia, el recurso de los sujetos a la justicia para resolver sus asuntos más íntimos merece una problematización de otras características. ¿Cuáles son las expectativas de los sujetos frente a la intervención judicial en sus problemas familiares?

¿Se trata de una búsqueda de procesos deliberativos diferentes a los que puede acceder un sujeto en una vida cotidiana empobrecida por las urgencias 
de supervivencia diaria? ¿Aparece en estos planteos una necesidad de regulación arbitral supraindividual que dirima planteos razonables y justos frente a otros parciales y centrados en la dinámica de la inmediatez?

\section{Nombre: $F$}

Denuncia: Adolescente que no deja entrar a su madre a la casa.

Esta denuncia "para que el juez se entere de su mal comportamiento".

No amerita resolución judicial

¿Cuál es la representación social de justicia que traen consigo estos sujetos a los que atraviesa la experiencia de la pobreza y de la exclusión social? ¿Existe una expectativa de sanción de conductas que ellos mismos consideran inaceptables y cuya percepción pretenden legitimar mediante un arbitraje imparcial? ¿Puede hablarse de cierta forma de imprevisión o de dificultad de medición de las implicaciones que estas denuncias intrafamiliares tienen en la vida de sus miembros?

La judicialización de los conflictos sociales y familiares produce efectos sobre los sujetos. El más inmediatamente perceptible a través de la lectura de los expedientes judiciales es una sobreexposición de las familias ante un sistema experto que los juzga, cataloga y etiqueta.

Los miembros de la familia quedan expuestos, de esta manera, ante la mirada inquisidora del experto que evalúa el "riesgo" de la situación presentada, desde una lectura abstracta de la que el sujeto no participa. El lenguaje del técnico, oscuro ante una relectura crítica que la familia podría realizar si el diagnóstico fuera devuelto con fines terapéuticos, cosifica los vínculos familiares que - como fotografía del presente — quedan alienados de aquéllos que los producen.

Al pasar al ámbito de la justicia, la familia pierde el control de la situación que atraviesa para verse, más tarde, reflejada en una decisión ajena sobre el conflicto que fuera expuesto al arbitraje público. Si bien una mirada distinta de terceros no implicados en un episodio que genera desazón en los miembros de la familia, podría enriquecer la instancia de elaboración del conflicto - me- 
diante un espacio en el que los sujetos pudieran "ver" de forma distanciada sus propias dificultades - la forma de "resolución" que se produce en el ámbito judicial no aporta una mirada crítica sobre la situación, con posibilidades de discusión para los participantes. Esta enajenación del conflicto puede, en efecto, ser iatrogénica para los actores, generando una segunda victimización de los sujetos por parte del sistema.

En segundo término, la exposición de los asuntos sociales ante la justicia implica una agudización de la tendencia hacia la individualización de los riesgos y la privatización de los problemas sociales (Bauman, 2002). Bajo la lupa del peritaje técnico los conflictos sociales desaparecen y se transforman en asuntos individuales frente a los que las personas no han logrado una solución satisfactoria.

\section{La Sra. piensa ocupar una casa.}

Está embarazada de tres meses. No está controlando. Fue una relación casual. Ya tiene ocho hijos, este sería el noveno. Ningún padre apoya. Los niños de 11 años y el de 7 piden monedas en la plaza [nombre].

- Se habla a la Sra. de la situación de sus hijos pidiendo.

- Se le explica cual es su responsabilidad.

- Se le explica que debe reclamar pensión alimenticia al padre de sus ocho hijos.

La forma y contenido de los diagnósticos analizados evidencian las particularidades de una intervención puntual en la vida de los sujetos en los que la figura de la mujer-madre aparece responsabilizada de la situación de desprotección en la que se encuentran sus hijos, en una disolución del conflicto que da origen a la desigualdad social.

Mediante el mecanismo de la individualización y culpabilización de sujetos portadores de los signos de la exclusión social, el dispositivo tecnocrático del diagnóstico deposita en el individuo la carga de una sociedad desigual y excluyente.

La práctica de judicializar los conflictos sociales va asociada a una naturalización de las desigualdades sociales que, a la vez que culpabiliza y estigma- 
tiza, expone a las personas que viven en condiciones de pobreza, al control y la supervisión del Estado.

V. [se hace referencia a la madre de estos niños] se encuentra muy negativa y exigente y no acepta ninguna solución. Se le ofrece Club de niños, de 8:30 a 13:30 por verano y CAIF para febrero para la niña de 2 años.

V. dice que no le sirve porque no le alcanza para alimentar a sus hijos o que tiene que trabajar muchas horas.

Se habló con [nombre] y acordamos que los tendrá hasta final de diciembre en [refugio diurno] dado que ni siquiera cobran por estos niños.

El peritaje técnico viene a confirmar, en tono sancionatorio y moralizante, la incapacidad del sujeto de resolver adecuadamente su vida cotidiana, eliminando todo trazo crítico hacia la sociedad productora de exclusión. En este esquema, la conducta se juzga desde parámetros sociales externos al sujeto y desde lógicas sociales productoras de expulsión y marginación.

\section{La fugacidad de la alarma social}

Una mirada de segundo orden al sistema de los Juzgados de Familia Especializados da cuenta de la instrumentación de un dispositivo de regulación que se activa mediante un sistema de alarma que funciona desde la respuesta de urgencia.

Esta perentoriedad de la respuesta arbitral frente a una situación de conflicto se mide a través de la celeridad de los diagnósticos elaborados en este contexto - en los que habitualmente se ve consignada esta limitación — tanto como de la presencia de la palabra arbitral del juez.

No obstante, esta premura tempranamente impulsada, que salta como un resorte apretado en una caja, se disuelve fácilmente cuando algunos de los mecanismos de búsqueda de información fracasan en la respuesta - no se encuentra a la persona buscada en su domicilio - o se otorga una "solución" que, aunque socialmente insatisfactoria, aparece como respuesta mágica que desactiva el dispositivo por orden del juez. 


\section{Nombre: M.}

Informe Servicio de Salud: Niño de 6 años diagnosticado con sífilis.

Por parte del centro asistencial se realiza: citación a la madre, atención médica, asistente social y psicólogo.

Juez solicita: informe social urgente a domicilio.

Se informa no encontrando el domicilio. Nuevo domicilio.

Informe social. 8/5/07.

El niño está atendido aunque sigue dando positivo el examen de sífilis. La madre informa que el concubino es de su total confianza.

Se archiva en base al informe social.

Nombre: C.

Denuncia: Recién nacido se encuentra a cargo de la abuela paterna en hospital.

Se cita al padre y a la abuela.

La niña pasa a vivir con sus padres.

La niña muere a los 5 meses por lo que se archiva el expediente.

Nombre: M.

Denuncia: Niño de 16 meses que no recibe cuidados adecuados de su madre, que no lo alimenta, no lo higieniza. Pulgas, ratas y perros en el domicilio.

Solicitud: Pericia médico forense e informe social a domicilio.

Informe social: No estaban en el domicilio. No concurrieron a entrevista.

Se archiva.

Este hipotético "fracaso" del sistema no lo invalida ante las representaciones sociales de la justicia, ni habla de una flexibilización de sus estructuras institucionales de asistencia. La aparente inconsistencia en la respuesta del sistema frente a situaciones conflictivas podría pensarse, en algún sentido, desde los procesos de selección que funcionan en todos los dispositivos de control social: desde la "captura" o la "detección precoz" a la internación.

Las situaciones anteriormente presentadas, en su inmensa mayoría, exponen ante el sistema judicial cuadros de pobreza, donde se destaca inicialmente y por la vía de la denuncia, la omisión de las responsabilidades adultas con respecto a los niños. 
El ámbito judicial en el área de la familia y el sistema de protección, opera y se reproduce con y a partir de estas circunstancias vitales. Es su materia hegemónica, si no exclusiva. Sin embargo, algunas de las situaciones que el sistema capta se disponen hacia los dispositivos de protección y otras se decantan, mayoritariamente, sin resolución y aparentemente desligadas de la gravedad inicial denunciada. ¿Qué elementos intervienen para que una determinada situación se inscriba en uno u otro tránsito?

¿Cómo se explica la fugacidad de la alarma social con la que se inicia la tramitación judicial de ciertas situaciones que irrumpen ante el sistema con ribetes de gravedad y luego se extinguen sin atención? ¿Es ésta una modalidad de respuesta de un sistema de control social cuya capacidad administrativa es inferior a la que requeriría la tramitación de la totalidad de las situaciones irregulares existentes?

\section{La institucionalización de niños y adolescentes como respuesta de protección}

Recuerda Marcelo Viñar (2004) que una de las acepciones que se le confiere al diagnóstico refiere al saber de una enfermedad a través de sus síntomas y signos y, por tanto, supone, por extensión, un juicio sobre un estado de cosas.

Nombre: R.

"Historia de uso problemático de drogas, mejoras en las últimas semanas viviendo situación de intenso estrés psicofísico presenta episodio de auto y heteroagresividad con ideación de muerte. Se efectúa heridas cortantes en ambos antebrazos decidiéndose trasladar a otro centro". [Indicación de medicación].

El diagnóstico que, como ya fue expuesto, no sólo es un conocimiento sobre el presente, sino que tiene efectos predictivos, se elabora desde una distancia cultural que no es meramente descriptiva sino que trae consigo "valoraciones afectivas y axiológicas" (Viñar, 2004: 35).

La lectura de los informes expertos presenta la peripecia de los niños atendidos en situación de urgencia e institucionalizados, a los que atraviesa el 
desamparo social y la ineficacia asistencial. Los sucesivos diagnósticos y derivaciones dan cuenta de la travesía de las familias por los pasillos burocráticos de una institución que no las protege, sino que muestra, - y, en este sentido, las intervenciones expertas aparecen reveladoras — su indefensión.

La denuncia de las situaciones familiares conflictivas activa un mecanismo de responsabilización de los adultos de referencia que, peritaje mediante, son encontrados incapaces de hacerse cargo de la crianza de los hijos, si se toma el caso de la maternidad-paternidad. Esta consideración técnica de dificultad de los adultos en relación al cuidado infantil es respondida con la institucionalización de estos niños o adolescentes. "Casos que son noticia diaria de abandono y mendicidad se repiten en madres que habiendo egresado de institutos ellas mismas, duplican la condición en sus hijos generando un retorno al circuito de la minoridad. Esta comprobación amplía la mirada con respecto a la profundidad de la condición de hacerse menor, en el sentido que estructura una subjetividad perdurable en el tiempo" (Costa y Gagliano, 2000: 85-6).

\section{Situación de A.}

Informe social y educativo social (Junio 2003).

Ingresó a la escuela y al (nombre de Centro Barrial), en su barrio de origen.

A partir de la intervención familiar es que se visualizan algunas dificultades para seguir avanzando en el proceso positivo al cual asistimos.

Algunas de esas dificultades son de orden económico (el padre se encuentra desempleado), mientras que los otros giran en torno a lo vincular. En relación a esto último consideramos que esta familia necesariamente debe reconstituir sus relaciones filiales y para ello se hace necesario generar un dispositivo que sostenga la revinculación hijos/as-padre. Para esto se hace necesario una separación de sus integrantes lo cual oficie de atenuante de las tensiones diarias, por lo que se solicita el ingreso a amparo por un tiempo acotado.

La estrategia sería que los niños de lunes a viernes estén en un hogar, retornando los fines de semana a su casa. Durante la semana se generará un espacio terapéutico para soporte del proceso.

Se solicita ingreso a (centro de internación).

Opera de esta forma, una mistificación de situaciones sociales complejas, donde la institucionalización es la respuesta y no necesariamente la so- 
lución, creándose así, la ilusión de solucionar la conflictividad social (Uriarte, 1999: 29).

Mediante este documento técnico, los sujetos son puestos, expuestos, en toda su vulnerabilidad, en un sistema de protección paradójicamente ineficiente. A partir del diagnóstico inicial, los niños y adolescentes internados transitan los corredores institucionales previstos para la minoridad. Costa y Gagliano identifican en cárceles y psiquiátricos el futuro previsible, la estación terminal de la minoridad, por oposición a la estación abierta y sin límites de la infancia. Como explican estos autores: "Los corredores llevan a itinerarios de individualización predeterminados, futuros previsibles" (2000: 77).

Situación de A.

Informe social y educativo social. ONG. (Junio 2003).

A través de sucesivas entrevistas con el padre, hemos podido observar que la situación que hoy está viviendo esta familia ha llevado a un nivel de angustia que impide en cierta forma retroalimentarse positivamente.

La internación de A y de sus hermanos es la mejor respuesta que hoy podemos dar para acompañar una serie de procesos positivos que desde hace un tiempo se viene generando.

Estamos ante un hogar con ingreso económico 0.

Junio 2003: se registra ingreso a Centro de Niñas del Instituto del Niño y el Adolescente del Uruguay (INAU).

Julio 2003: se entrega a su padre quien no la quería recibir. Ya lo había planteado en el Centro de Estudio y Derivación (CED).

2005: Reingresa a INAU por factores económicos.

2007: Internación en Centro INAU.

Informe División de Estudio y Derivación (DED antiguo CED) (Octubre 2007) Se presenta en la DED con 13 años. Hace días se encuentra en situación de calle. Pernoctó ayer en el Hogar Transitorio. Egresó del centro de internación con su madre, pero surgieron dificultades de convivencia, sobre todo con una hermana por lo que se niega rotundamente a volver a su casa. Asiste a la maestra de apoyo de ONG. Dice no contar con referentes familiares, por lo que se acuerda su reingreso. 
Informe Centro INAU (Junio 2008).

Protagoniza sucesos de heteroagresividad en el Hogar.

Impresiona con bajo nivel intelectual.

No culminó escuela. Hizo hasta $5^{\circ}$ año.

Núcleo familiar constituido por ambos padres: madre (ama de casa) y padre (requechero). Tiene 6 hermanos, 3 se encuentran en (nombre centro).

Niega consumo de drogas.

Refiere maltrato físico por parte de la familia por lo que no quiere regresar a su núcleo familiar.

Joven impulsiva con riesgo para sí misma y/o terceros.

Se dispone internar en Clínica (nombre clínica de atención psiquiátrica)

Sería conveniente pensar en un Hogar que no sea el centro anterior luego del alta, que pueda tener una atención más personalizada y pueda controlar sus crisis.

Noviembre 2008. Detención por presunción de infracción.

Ingresa al Centro de INTERJ.

Traslado a Centro de Protección de Tiempo Completo.

El tránsito por los corredores y pasadizos de la minoridad, inventa, modela y reproduce $e^{10}$ la figura del menor - construcción devaluada y estigmatizada de la infancia — de tal forma que "abandono e infracción se transforman en una impronta personal, en algo que pertenece al ser del sujeto, no se trata tanto de un adolescente en abandono o en infracción, sino de un abandonado y de un infractor" (Uriarte, 1999: 27). La situación, se "vuelve él", sintetiza Uriarte.

Para la doctrina de la situación irregular, "en riesgo social” se encuentran los menores comprendidos en términos de abandono moral y/o material e infracción. La categoría de abandono — definida como la columna vertebral de la doctrina - remite a cuadros de pobreza donde las configuraciones familiares guardan distancia con el modelo nuclear, los niños se ubican más en calle que en situación de aprendizaje escolar y los adultos incumplen sus funciones paternas de provisión y protección. Desde esta perspectiva, se consagra además,

10. Las expresiones corresponden a Emilio García Méndez (1994). Ver también Carlos Uriarte (1999) y (2006). 
la indistinción entre abandono e infracción, en tanto, el abandono lleva al delito, y este a su vez, es un momento del abandono.

Carlos Uriarte señala que esta definición normativa traduce la preocupación del legislador, que es moral, pero que también es una preocupación física: "Para el legislador hay una época escolar y una época laboral y momentos familiares de fondo, en los intersticios restantes [...] que tienen sus tiempos, pero también lugares de continencia [...]. El abandono moral de la pobreza, paradójicamente, es también físico porque no hay escuela, porque hay que trabajar y porque no hay continencia física en el grupo de crianza”. (Uriarte, 1999: 46).

Operar desde el ámbito judicial y el sistema de protección social con la categoría de abandono, así entendida, supuso para la concepción tutelar, un posicionamiento que, al unísono, seleccionaba para la atención, ciertos cuadros de pobreza, los definía en términos de abandono, enunciaba propósitos de protección, y terminaba actuando desde un enfoque de defensa social, protegiendo a la sociedad de un sujeto, inicialmente abandonado y finalmente infractor, quien resultaba colocado en los pasadizos y corredores institucionales de la minoridad (Erosa e Iglesias, 2000).

Salvar al pobre, - y en particular salvar a la infancia pobre - esa era la empresa a emprender desde la Doctrina de la Situación Irregular, heredera del Movimiento de los Reformadores, impulsando el disciplinamiento y condenando las prácticas cotidianas y las concepciones morales de los hijos de la pobreza. ${ }^{11}$

\section{El paradigma opuesto: desinstitucionalizar como consigna de protección integral}

Si la institucionalización funcionó, desde la perspectiva tutelar, como mecanismo de respuesta estatal frente a dificultades familiares de provisión y protección de sus miembros más débiles, la década del ' 90 vio surgir una pers-

11. Para un análisis del Movimiento de los Reformadores, ver: PLATT, A. Los "salvadores del niño" o la invención de la delincuencia. México, Siglo XXI. 1982. 
pectiva crítica que buscó rescatar la voz del sujeto en una institución que lo condenaba al anonimato. ${ }^{12}$

La búsqueda de las singularidades biográficas y el énfasis en los procesos de subjetivación iniciaron un camino donde los "menores" se convertían en "niños y adolescentes" cuyas trayectorias vitales era preciso ubicar en perspectiva histórica.

Este énfasis en los derechos de niños y adolescentes de ambos géneros, propició un redescubrimiento de la relación parental para el desarrollo del sujeto sano, reescribió la relación con los técnicos — cada vez más presentes en las instituciones - y estimuló el ensanchamiento de la visibilización jurídica de la infancia y la adolescencia.

Leídos como escalones hacia una mirada "integral" de la infancia, estos nuevos énfasis fueron positivamente percibidos por activistas y organizaciones sociales, actores públicos y privados que encabezaban la lucha por los derechos de la infancia.

Sin embargo, paralelamente a estos desarrollos conceptuales en el campo de la infancia, en la década del '80 - aunque de tardía influencia en Latinoamérica - se inicia una lectura sociológica que habla de la responsabilidad del sujeto en su propia vida, que relativiza los condicionamientos estructurales y recurre a la reflexividad moderna para cambiar destinos individuales que ya no aparecen socialmente delimitados. Con distintos énfasis, los autores de la modernidad reflexiva sitúan al sujeto en un marco social y ambiental que deberá tener en cuenta para calcular oportunidades, desafíos y riesgos en un diseño biográfico que está llamado a construir individualmente.

Esta nueva lectura de un sujeto que conquista su libertad en un entorno de creciente reflexividad, trae como contrapartida su responsabilidad en decisiones cada vez más informadas.

Estas dos lecturas teóricas, - la doctrina de la protección integral y la perspectiva de la modernidad reflexiva - sustentadas en presupuestos diferen-

12. Cabe aclarar que, desde la perspectiva tutelar, el anonimato se genera como resultado de una construcción conceptualmente homogeneizadora de la minoridad que, en la práctica, dispone de iguales dispositivos institucionales para su tratamiento, lo que permite hablar de "corredores preestablecidos" para la infancia institucionalizada. 
tes, tienen su punto de contacto en la centralidad atribuida al sujeto. Por un lado, la perspectiva de la protección integral pone el acento en los procesos de subjetivación del niño en su crecimiento, en estrecha vinculación con su entorno familiar de origen. Por otra parte, los analistas del riesgo centran su atención en la autoconstrucción reflexiva del yo en contextos de incertidumbre.

El punto de contacto entre estas dos miradas ha dado lugar a superposiciones y confusiones en las discusiones conceptuales desarrolladas en el ámbito nacional.

La ubicación del sujeto en el centro del debate de los derechos del niño ha generado una crítica a las instituciones asistenciales y un movimiento de promoción de la desinstitucionalización de niños y adolescentes que las habitaban.

Los nuevos desarrollos de la doctrina de protección integral tienen a enfatizar los derechos del niño a tener contacto cercano y convivir con su familia de origen. La internación funciona como "último recurso", a partir de la Convención Internacional de los Derechos del Niño y del Código de la Niñez y la Adolescencia en Uruguay, configurando un nuevo escenario que "devuelve" a la familia, cuestionada en el desempeño de sus funciones de protección y cuidado, la responsabilidad de su propia reproducción.

Esta vuelta del niño a su familia, considerada ámbito natural de desarrollo del sujeto por la perspectiva de protección integral, tiene su correlato en la "política de la vida" de la que habla Giddens (1995), mediante la cual el sujeto es el único responsable de sí mismo y de aquéllos que de él dependen.

Sin embargo, la celebración de la autoconstrucción de la trayectoria biográfica por parte de sujetos responsables se superpone también con las nuevas tendencias a la desresponsabilización pública de la vida de los individuos más vulnerables.

\section{CED-INAU}

Se presenta la Sra. R. planteando que tiene graves problemas económicos y la están por echar de la pensión. La AS. del hogar [nombre] [le dijo] que desde el centro le podrían pagar sólo un mes de pensión, que después se tenía que arreglar por ella misma. 
Plantea que ella está con 4 hijos a su cargo ya que su hijo mayor T. de 8 años está con su abuela materna.

Su compañero trabaja cuando quiere, a veces solo me trae \$50 por día. Ella no trabaja ya que está a cargo del bebé que es un niño muy complicado desde el punto de vista de la salud.

$M i$ compañero no se queda a cuidar al niño, yo ya varias veces le he planteado la separación ya que no coopera en nada. El padre de F. sí me ayuda cuando puede. Le está haciendo un juicio al papá de la grande para cobrar pensión alimenticia. No hay ¿? Su compañero, él no consume alcohol ni drogas, estoy con él si no, no puedo pagar la pensión.

La demanda de la Sra. era internar a sus hijos. Se le explica que no se interna a los niños que tienen familia y que además están cubiertos por dos instituciones del INAME.

¿No es esta situación, en cierta forma, ejemplo de lo que Castel identifica como la estrategia de "asegurarse a sí mismo", en tiempos en que se celebra al individuo aislado de sus inserciones colectivas? (Castel, 2005: 85).

\section{Consideraciones finales}

En contextos de incertidumbre y múltiples alternativas de elección, la confianza en los sistemas abstractos constituye un requerimiento básico de la producción y reproducción social moderna, tanto para expertos como para no especialistas. ${ }^{13}$ Sin embargo, la reflexividad intrínseca a los sistemas expertos sólo puede ser garantizada por la revisión continua de sus fundamentos, procedimientos y contenidos a partir de una constante actualización instrumental y sustantiva. $^{14}$

13. "La confianza en los mecanismos de desenclave no es sólo cosa de los profanos, pues nadie puede ser experto más que en una mínima parte de los diversos aspectos de la vida social moderna, condicionada por sistemas abstractos. Cualquiera que viva en condiciones de modernidad se verá afectado por una multitud de sistemas abstractos y sólo podrá obtener, en el mejor de los casos, un conocimiento superficial de sus tecnicismos" (Giddens, 1995: 36).

14. "La modernidad institucionaliza el principio de la duda radical y recalca que todo conocimiento adopta la forma de hipótesis, de afirmaciones que pueden muy bien ser ciertas, pero que en principio son siempre susceptibles de revisión y pueden ser abandonadas en algún momento" (Giddens, 1995: 11). 
Por lo expuesto y con la intención de ser sometido a discusión, este trabajo se propone como un ejercicio de reconocimiento de los supuestos de sustentación de las prácticas diagnósticas elaboradas en el marco del sistema sociojudicial uruguayo.

Como ya fuera consignado, el diagnóstico, como práctica social en el ámbito sociojudicial, surge de un encuentro de carácter desigual entre un sujeto que expone su trayectoria biográfica y un experto que la decodifica, devolviendo una mirada especializada y reinterpretada de sus conflictos.

De esta forma, la descripción y juicio experto expropia de los sujetos su versión del asunto, que vuelve a ellos en forma de decisión abstracta con consecuencias prácticas sobre su vida privada. Desde una lectura que parece surgir de la concepción reflexiva de la tardía modernidad, el diagnóstico se elabora como un juicio ajeno sobre un conflicto privado que resuelve acerca de la capacidad del sujeto para manejar asuntos en los que se lo considera responsable.

Desde esta perspectiva, los actores sociales son progresivamente liberados de las determinaciones institucionales y sociales que restringían su capacidad de tomar decisiones poniéndolos frente a multiplicidad de opciones y riesgos (Giddens, 1995; Luhmann, 1992; Beck, 1997, 1998, 2001).

El cuerpo de expertos retoma el lenguaje del riesgo a partir del supuesto de la construcción autorreflexiva de la biografía de sujetos que disponen de la información necesaria para asumir responsablemente las consecuencias de sus decisiones y dar cuenta de sus conductas de forma racional. Se concibe entonces, un ser humano que, en palabras de Beck, "es capaz de escoger, decidir y crear, que aspira a ser autor de su propia vida, creador de una identidad individual" (2001: 234).

De esta manera, continúa Beck, los hechos de la vida no se atribuyen a "causas ajenas", "sino a aspectos del individuo (decisiones, indecisiones, omisiones, capacidades, incapacidades, logros, concesiones, derrotas)" (Beck, 2001: 238).

En esta forma de medición de las trayectorias de vida, el desempleo, las enfermedades, las adicciones, las dificultades en el ejercicio de roles familiares son exclusiva responsabilidad individual (Bauman, 2002). En estos escenarios de 
evaluación, la pobreza aparece como un fracaso de la estrategia individual de conducir la existencia propia y de la familia. Si las vicisitudes que atraviesa la vida de una familia pobre son producto de decisiones responsablemente asumidas en función de un cálculo sopesado de riesgos, las desigualdades sociales quedan invisibilizadas en una mirada tecno-instrumental que se especializa en describir trayectorias vitales y evaluar la pertinencia de las decisiones adoptadas.

Mediante este sofisticado mecanismo de atribución de responsabilidades, el informe diagnóstico descontextualiza el análisis de los conflictos sociales que surgen en una sociedad excluyente, cuya desigualdad no es posible resolver desde lógicas individuales y voluntarias.

Se borran así vulnerabilidades socialmente inscriptas en una sociedad de clases, atribuyendo a los sujetos individuales y a los grupos familiares más frágiles y desestabilizados la responsabilidad de conductas que atentan contra una concepción aséptica de salud pública y de orden social que se define previamente.

De esta forma se estigmatiza la pobreza, que es tratada en función de la irresponsabilidad social de los sectores excluidos, a los que se culpabiliza de su situación de minoridad social.

Como argumenta Bauman, contraponiendo la perspectiva de los analistas del riesgo y su visión de la responsabilidad colectiva en la privatización de los asuntos sociales, "El poder de licuefacción se ha desplazado del "sistema" a la "sociedad", de la "política" a las "políticas de la vida"... o ha descendido desde el "macronivel" al "micronivel" de la cohabitación social. Como resultado, la nuestra es una visión privatizada de la modernidad, en la que el peso de la construcción de pautas y la responsabilidad del fracaso caen primordialmente sobre los hombros del individuo" (Bauman, 2002: 13).

En definitiva, la vida propia que enuncia Beck (2001) - y que brega por la realización y el triunfo individual - supone que el fracaso también es propio.

No obstante, si bien las instituciones sociales son denunciantes de conductas riesgosas, el acceso a la justicia en el tratamiento de asuntos de familia es un recurso valorado y buscado — también y fundamentalmente - por los sectores sociales más vulnerables. El trabajo plantea algunas preguntas que pueden orientar el análisis futuro en estas cuestiones. 
Asimismo, cabe señalar, la vigencia que se observa en torno al uso del bagaje conceptual que configuró, en Uruguay y en el continente, la perspectiva tutelar en el campo de la niñez y adolescencia. En este sentido, cuando el discurso experto explicita el contenido atribuido a la categoría de riesgo social, la antigua conceptualización de abandono moral emerge con nitidez.

Así, es posible reconocer la sugerencia de institucionalización como respuesta a un conflicto vincular en niños y adolescentes que son caracterizados desde la perspectiva tutelar como menores, a los que les espera un futuro previsto por los "corredores y pasadizos" de las instituciones asistenciales, en el lenguaje utilizado por Costa y Gagliano.

Pero, por otro lado, en oposición a esta lectura institucionalizadora, la perspectiva de la desinsititucionalización no aparece más continente o respetuosa de la infancia pobre. En una mezcla del paradigma de la protección integral con la perspectiva de la modernidad reflexiva, los sectores vulnerables son instados a asumir la responsabilidad de su propia reproducción social, desde una lectura que contribuye a invisibilizar las desigualdades y alivia la responsabilidad social del Estado.

Artigo recebido em junho/2009 - Aprovado em dez./2009

\section{Referências bibliográficas}

BAUMAN, Z. Modernidad líquida. Buenos Aires, Fondo de Cultura Económica, 2002.

BECK, U. "Vivir nuestra propia vida en un mundo desbocado: individuación, globalización y política”, en: GIDDENS, A.; HUTTON, W. (eds.) En el límite. La vida en el capitalismo global. Barcelona, Kriterios TusQuets. 2001.

La sociedad del riesgo: hacia una nueva modernidad. Barcelona, Paidós, 1998.

BECK, U. et al. Modernización reflexiva. Política, tradición y estética en el orden social moderno. Madrid, Alianza Universidad, 1997.

CASTEL, R. "De la peligrosidad al riesgo", en: Materiales de Sociología crítica. Madrid, La Piqueta, 1986. 
CASTEL, R. "Encuadre de la exclusión”, en: Karsz, S. (coord.) La exclusión: bordeando sus fronteras. Definiciones y matices. Barcelona, Gedisa, 2005.

CASTEL, R. La inseguridad social ¿Qué es estar protegido? Buenos Aires, Manantial, 2004.

COSTA, M.; GAGLIANO, R. "Las infancias de la minoridad", en: DUSCHANTZKY, S. (comp.) Tutelados y asistidos. Programas sociales, políticas públicas y subjetividad. Buenos Aires, Paidós, 2000.

EROSA, H; IGLESIAS, S. La construcción punitiva del abandono. Serie materiales de apoyo. Montevideo, CENFORES. INAU, 2000.

FOUCAULT, M. La verdad y las formas jurídicas. Barcelona, Gedisa, 1991.

Los anormales. Buenos Aires, Fondo de Cultura Económica, 2007.

GARCÍA MÉNDEZ, E. Derecho de la infancia-Adolescencia en América Latina: de la Situación Irregular a la Protección Integral. Santa Fe de Bogotá, Ediciones Forum Pacis, 1994.

GIDDENS, A. Consecuencias de la modernidad. Madrid, Alianza Editorial, 1994. Modernidad e identidad del yo. Barcelona, Península, 1995.

GONZÁLEZ, C. "La pericia social: una producción colectiva de saber acerca de los conflictos sociales en contextos de urgencia. El caso de los Juzgados de Familia Especializados", Espacio Abierto, Año IV, No 8, Mayo 2008. p. 81-90.

HABERMAS, J. La teoría de la acción comunicativa. Madrid, Taurus, 1987.

LUHMANN, N. Sociología del riesgo. México, Universidad Latinoamericana/Universidad de Guadalajara, 1992.

PLATT, A. Los "Salvadores del Niño" o la invención de la delincuencia. México, Siglo XXI, 1982.

URIARTE, C. Control institucional de la niñez adolescencia en infracción. Un programa mínimo de contención y límites jurídicos al Sistema Penal Juvenil (las penas de los jóvenes). Montevideo, Carlos Álvarez Editor, 1999.

. Vulnerabilidad, privación de libertad de jóvenes y derechos humanos. Montevideo, FCU. CENFORES — INAU. 2006.

VIÑAR, M. "Sobre el diagnóstico de vulnerabilidad. Ventajas y riesgos", en: VVAA "Diagnóstico de Vulnerabilidad". Montevideo, CENFORES. INAME. OPP. AECI. 2004. 